\title{
Antiretroviral drug resistance mutations among patients failing first-line treatment in Hanoi, Vietnam
}

\author{
Tran Viet Tien' \\ Dinh Cong Pho ${ }^{2}$ \\ Le Thu Hong ${ }^{3}$ \\ Hien Pham $\mathrm{Ba}^{4}$ \\ Le Van Nam' \\ Pham Ngoc Hung ${ }^{5,6}$ \\ 'Department of Infectious Diseases, \\ Military Hospital 103, Vietnam Military \\ Medical University, Hanoi City, Vietnam; \\ ${ }^{2}$ Faculty of Medicine, Vietnam Military \\ Medical University, Ha Dong District, \\ Hanoi City, Vietnam; ${ }^{3}$ Department of \\ Microbiology, Military Hospital 103, \\ Vietnam Military Medical University, \\ Hanoi City, Vietnam; ${ }^{4}$ Department of \\ Infectious Diseases, Dong Da Hospital, \\ Hanoi City, Vietnam; ${ }^{5}$ Department of \\ Epidemiology, Vietnam Military Medical \\ University, Hanoi City, Vietnam; \\ ${ }^{6}$ Department of Training, Vietnam \\ Military Medical University, Hanoi City, \\ Vietnam
}

This article was published in the following Dove Press journal: Infection and Drug Resistance
Objectives: To study the prevalence of drug resistance and genotype testing for HIV drug resistance on HIV/AIDS patients with first-line antiretroviral treatment failure at Dong Da Hospital, Hanoi, Vietnam.

Patients and methods: Forty-seven patients in Dong Da Hospital, Hanoi, with confirmation of first-line antiretroviral therapy (ART) failure were enrolled in this study from June 2006 to December 2016. Both the protease and reverse transcriptase genes were amplified and sequenced using Trugene ${ }^{\circledR}$ HIV-1 Genotyping Kit and OpenGene ${ }^{\circledR}$ DNA system at the biomolecular laboratory of the National Institute of Hygiene and Epidemiology, Vietnam. The Stanford HIV database algorithm was used for interpretation of resistance data and genotyping.

Results: Drug resistance mutations were $90.7 \%$ in patients with first-line treatment failure. Amongst patients with drug resistance mutation, 97.7\% resisted to non-nucleoside reverse transcriptase inhibitors (NNRTIs), followed by nucleoside reverse transcriptase inhibitors (NRTIs, 95.3\%) and protease inhibitors (PIs, 11.6\%). Amongst the genetic mutations resistant to NNRTIs, G190S mutation was the highest (51.2\%), K101HQ mutation was 39.5\% and Y181I mutation was 34.9\%. In genetic mutations to NRTIs, M184V mutation was $88.4 \%$. In thymidine analogue mutations, K70R mutation was the most common $(37.2 \%)$, followed by $\mathrm{D} 67 \mathrm{~N}, \mathrm{~T} 215 \mathrm{~F}$ and $\mathrm{T} 69 \mathrm{~N}$ mutations $(27.9 \%, 27.9 \%$ and $25.6 \%$, respectively). In genetic mutations in PIs, M36I and K20R mutations made up 9.3\%. In NNRTIs, the prevalence of nevirapine resistance was $55.8 \%$, and that of efavirenz resistance was $4.7 \%$. In NRTIs, the ratio of lamivudine resistance was $93.0 \%$, and that of zidovudine resistance was $9.3 \%$. No lopinavir/ritonavir resistance was recorded.

Conclusions: Drug resistance mutations in patients with first-line ART failure had a high prevalence of NNRTI and NRTI resistance but still susceptible to PIs.

Keywords: HIV-1 drug resistance, first-line antiretroviral therapy failure, genetic mutation for drug resistance, virological failure

\section{Introduction}

HIV is a public health issue. In 2017, 21.7 million patients were receiving antiretroviral therapy (ART). ${ }^{1}$ ART improves the quality of life and survival of HIV patients and controls HIV transmission; however, these benefits can be limited by HIV-1 drug resistance (HIV-DR). ${ }^{2}$ Moreover, this condition can severely limit the treatment options for new patients and shorten the time to treatment failure. ${ }^{3}$ The
Correspondence: Pham Ngoc Hung Vietnam Military Medical University, 160 Phung Hung Road, Ha Dong District, Hanoi City, Vietnam

Email pnhungqy@vmmu.edu.vn 
mutation patterns associated with HIV-DR are complex, and the resistance to other drugs develops when the failed regimens continue to be given. ${ }^{4}$

In Vietnam, the public health approach to providing highly active ART was rolled out in 2005, and a free national program was then rapidly expanded. There are growing concerns about the occurrence and spread of HIV-DR in Vietnam. HIV-DR prevalence $(6-8 \%)$ is reported amongst high-risk populations (such as female sex workers and injecting drug users). ${ }^{5,6}$ This prevalence is persistently low $(<5 \%)$ in Northern Vietnam ${ }^{7}$ and low to moderate $(2.4-5.48 \%)$ in Southern Vietnam ${ }^{8}$ despite that it slightly increased from $1.8 \%$ in 2007 to $6.6 \%$ in 2012 in Haiphong (Northern Vietnam).

The existence of HIV-DR is significantly associated with the early development of virological failure. The initial treatment choice should be based on resistance testing in treatment-naive patients. ${ }^{9}$ However, in Vietnam, viral load and HIV-DR genotypic test are only recommended for people who are suspected of a clinical or immunological failure of first-line treatment. ${ }^{10}$

In Vietnam, data on HIV-DR amongst people with firstline therapeutic failure are limited. Thus, this study investigated the patterns of HIV-DR amongst adults (age $>18$ years) diagnosed with first-line ART failure according to the WHO guidelines in a northern major city, Hanoi, Vietnam.

\section{Materials and methods}

\section{Study population and data collection}

In this study, the inclusion criteria of participants were as follows: adults ( $>18$ years old) who received first-line ART regimens according to the National Guideline in $2005^{11}$ for more than 6 months and those who had certain WHO criteria for immunological or clinical treatment failure. The participants were enrolled in this study between June 2006 to December 2016 at Dong Da Hospital, Hanoi,Vietnam.

The first-line ART regimens comprised two nucleoside/ nucleotide reverse transcriptase inhibitors (NRTIs) along with a non-nucleoside reverse transcriptase inhibitor (NNRTI) (including ZDV/3TC/NVP regimen: zidovudine $[\mathrm{ZDV}]+$ lamivudine $[3 \mathrm{TC}]$ and nevirapine [NVP] or $\mathrm{d} 4 \mathrm{~T} /$ 3TC/NVP regimen: stavudine $[\mathrm{d} 4 \mathrm{~T}]+$ lamivudine $[3 T C]+$ nevirapine $[N V P])$. Patients consented to participate in the study and were excluded from the study when they did not follow the protocol. A diagnosis of treatment failure was made according to WHO guidelines. ${ }^{12}$
HIV drug resistance mutation testing was ordered based on the plasma viral load, and 47 patients with virological failure who had a viral load of 1,000 copies/ $\mathrm{ml}$ or above at the time of analysis were selected for genotyping analysis. Blood samples of 47 patients were collected, and the plasma specimens were stored in standard criteria for analyses. Sample collection was performed at the biomolecular laboratory of the National Institute of Hygiene and Epidemiology.

\section{Drug resistance genotyping and drug resistance analyses}

Drug resistance was evaluated by sequencing reverse transcriptase and protease genes that were amplified and sequenced using the Trugene ${ }^{\circledR}$ HIV-1 Genotyping Kit and OpenGene ${ }^{\circledR}$ DNA system. ${ }^{13}$ We used the Stanford Database to assess and determine the DR mutation profile of all sequences (available at http://hivdb.stanford.edu/). The virus is defined as susceptible to an HIV medication if the total score for that drug is 9 or less, whereas low-level, low-level, intermediate-level and high-level resistance to ARV is identified if the total score is $10-14,15-29,30-59$ or $\geq 60$, respectively.

\section{Ethics statement}

The protocol was approved by the Ethics Committee of Hanoi City. The study was in line with the Declaration of Helsinki. Before the collection of blood samples, written informed consent was provided to all participants after a thorough explanation of the purpose of this study. Moreover, patients had the right to discontinue at any time during the study.

\section{Statistical analysis}

The statistical analysis was conducted using the SPSS version 20.0 package (IBM Corporation, Armonk, NY, USA). Descriptive analyses were performed by calculating the mean and standard deviation, median and interquartile range and the frequency.

\section{Results}

In 47 patients with first-line treatment failure, 43 (90.7\%) had drug resistance mutations. The characteristics of patients who failed first-line treatment are shown in Table 1.

According to the drug resistance mutations, 97.7\% resisted to NNRTIs, followed by NRTIs (95.3\%) and PIs (11.6\%). More details are shown in Table 2. 
Table I Demographics of 47 patients with first-line treatment failure

\begin{tabular}{|c|c|c|}
\hline Demographic variable & Value & Note \\
\hline $\begin{array}{l}\text { Gender: n (\%) } \\
\text { Male } \\
\text { Female }\end{array}$ & $\begin{array}{l}30(63.8) \\
17(36.2)\end{array}$ & \\
\hline $\begin{array}{l}\text { Age: } n(\%) \\
\quad<30 \text { years } \\
30-39 \text { years } \\
40-49 \text { years }\end{array}$ & $\begin{array}{l}3(6.4) \\
4 I(87.2) \\
3(6.4)\end{array}$ & $\begin{array}{l}\text { Mean } \pm \text { SD } \\
34.15 \pm 4.03\end{array}$ \\
\hline $\begin{array}{l}\text { Duration of first-line ART use } \\
\text { (months) } \\
\text { Mean } \pm \text { SD } \\
\text { Male } \\
\text { Female } \\
\text { Total }\end{array}$ & $\begin{array}{l}54.48 \pm 27.99 \\
36.80 \pm 19.23 \\
46.81 \pm 26.09\end{array}$ & $\begin{array}{l}\text { Min-Max } \\
\text { (months) } \\
9.07-111.30 \\
7.73-81.07 \\
7.73-111.30 \\
\text { p-value }=0.046\end{array}$ \\
\hline $\begin{array}{l}\text { Initial first-line regimen } \\
\text { d4T/3TC/NVP } \\
\text { ZDV/3TC/NVP }\end{array}$ & $\begin{array}{l}31(66.0) \\
16(34.0)\end{array}$ & \\
\hline $\begin{array}{l}\text { Risk factor } \\
\text { Injecting drug user } \\
\text { Sexual exposure } \\
\text { Injecting drug user and Sexual } \\
\text { exposure }\end{array}$ & $\begin{array}{l}18(38.3) \\
18(38.3) \\
11(23.4)\end{array}$ & \\
\hline $\begin{array}{l}\text { CD4 cell count } \\
\quad<50 \\
50-99 \\
100-199 \\
200-349 \\
\geq 350\end{array}$ & $\begin{array}{l}16(34.0) \\
16(34.0) \\
7(14.9) \\
8(17.1) \\
0(0)\end{array}$ & \\
\hline
\end{tabular}

Abbreviation: ART, antiretroviral therapy.

Amongst the genetic mutations resistant to NNRTIs, G190S mutation was the highest (51.2\%), K101HQ mutation was $39.5 \%$, and Y181I mutation was $34.9 \%$ (Table 3).

In genetic mutations to NRTIs, M184V was the most common ARV-resistant pattern (88.4\%). In thymidine analogue mutations (TAMs), K70R mutation was the most common (37.2\%). The proportions of D67N and T215F mutations were $27.9 \%$ and $27.9 \%$, respectively (Table 4).

In genetic mutations to PIs, M36I and K20R mutations made up 9.3\% (Table 5).

In NNRTIs, the prevalence of nevirapine resistance was $55.8 \%$, and that of efavirenz resistance was $4.7 \%$. In NRTIs, the ratio of lamivudine resistance was $93.0 \%$, and that of zidovudine resistance was $9.3 \%$. No lopinavir/ ritonavir resistance was recorded (Table 6).
Table 2 Frequency of drug resistance mutations by drug class

\begin{tabular}{|l|l|l|}
\hline $\begin{array}{l}\text { Gene resistance } \\
\text { mutations }\end{array}$ & $\begin{array}{l}\text { Number of } \\
\text { patients } \\
\text { (Total: } \\
\text { n=43) }\end{array}$ & $\begin{array}{l}\text { Percentage } \\
\text { (\%) }\end{array}$ \\
\hline NNRTI resistance & 42 & 97.7 \\
NRTI resistance & $4 \mathrm{I}$ & 95.3 \\
PI resistance & 5 & 11.6 \\
NNRTI + NRTI resistance, & 35 & 81.4 \\
Non-resistance with PI & 5 & 11.6 \\
NNRTI + NRTI + PI resistance & 5 & 4.7 \\
NNRTI resistance, & 2 & 2.3 \\
Non-resistance with NRTI and PI & & \\
NRTI resistance, Non-resistance & 1 & \\
with NNRTI and PI & & \\
\hline
\end{tabular}

Abbreviations: NRTI, nucleoside reverse transcriptase inhibitor; NNRTI, nonnucleoside reverse transcriptase inhibitor; Pl, protease inhibitor.

Table 3 Frequency of NNRTI resistance

\begin{tabular}{|c|c|c|c|}
\hline $\begin{array}{l}\text { Type of } \\
\text { mutation }\end{array}$ & Frequency & $\begin{array}{l}\text { In ARV drug } \\
\text { resistance } \\
(n=43)\end{array}$ & $\begin{array}{l}\text { In first-line } \\
\text { ARV failure } \\
(n=47)\end{array}$ \\
\hline A98G & 3 & 7.0 & 6.4 \\
\hline $\mathrm{M} 230 \mathrm{~L}$ & I & 2.3 & 2.1 \\
\hline $\mathrm{KIOIH}$ & 6 & 14.0 & 12.8 \\
\hline KIOIE & 10 & 23.3 & 21.3 \\
\hline KIOIPQ & 1 & 2.3 & 2.1 \\
\hline KIOIEQ & I & 2.3 & 2.1 \\
\hline KIOIHQ & 17 & 39.5 & 36.2 \\
\hline $\mathrm{K} 103 \mathrm{~N}$ & I & 2.3 & 2.1 \\
\hline GI90S & 22 & 51.2 & 46.8 \\
\hline GI90A & I & 2.3 & 2.1 \\
\hline YI8II/C/V & 15 & 34.9 & 31.9 \\
\hline YI8IC & I & 2.3 & 2.1 \\
\hline YI8IV & 3 & 7.0 & 6.4 \\
\hline YI88L & 3 & 7.0 & 6.4 \\
\hline V106I & I & 2.3 & 2.1 \\
\hline VI08I & I & 2.3 & 2.1 \\
\hline VI79T & 3 & 7.0 & 6.4 \\
\hline YI79D & I & 2.3 & 2.1 \\
\hline VI79E & I & 2.3 & 2.1 \\
\hline $\mathrm{P} 225 \mathrm{H}$ & 2 & 4.7 & 4.3 \\
\hline
\end{tabular}

Abbreviations: ARV, antiretroviral; NNRTI, non-nucleoside reverse transcriptase inhibitor.

\section{Discussion}

In previous studies using specimens from voluntary counseling and testing, the prevalence of HIV-DR was persistently low $(<5 \%)$ in the north, ${ }^{14}$ but this level appears to increase rapidly from $<5 \%$ in $2006^{15}$ to $5 \%-15 \%$ in $2007-2008$ in the southern areas. ${ }^{16}$ The prevalence of circulating ART-resistant 
Table 4 Frequency of NRTI resistance

\begin{tabular}{|c|c|c|c|}
\hline $\begin{array}{l}\text { Type of } \\
\text { mutation }\end{array}$ & Frequency & $\begin{array}{l}\text { In ARV drug } \\
\text { resistance } \\
(n=43)\end{array}$ & $\begin{array}{l}\text { In first-line } \\
\text { ARV failure } \\
(n=47)\end{array}$ \\
\hline D67N* & 12 & 27.9 & 25.5 \\
\hline V75M & 16 & 37.2 & 34.0 \\
\hline V75IM & 1 & 2.3 & 2.1 \\
\hline VI06I & 2 & 4.7 & 4.3 \\
\hline VI08I & 5 & 11.6 & 10.6 \\
\hline VII8I & 4 & 9.3 & 8.5 \\
\hline K65R & 5 & 11.6 & 10.6 \\
\hline K70R* & 16 & 37.2 & 34.0 \\
\hline KIOIQ & 2 & 4.7 & 4.3 \\
\hline $\mathrm{KIOIH}$ & 2 & 4.7 & 4.3 \\
\hline $\mathrm{K} 2 \mathrm{IOR}$ & I & 2.3 & 2.1 \\
\hline $\mathrm{K} 219 \mathrm{E}^{*}$ & 4 & 9.3 & 8.5 \\
\hline K219E/Q* & 2 & 4.7 & 4.3 \\
\hline K219Q* & 7 & 16.3 & 14.9 \\
\hline T69D & 2 & 4.7 & 4.3 \\
\hline T69N & II & 25.6 & 23.4 \\
\hline T2I5Y & 2 & 4.7 & 4.3 \\
\hline $\mathrm{T} 215 \mathrm{~F}^{*}$ & 12 & 27.9 & 25.5 \\
\hline T2I5FS & 1 & 2.3 & 2.1 \\
\hline $\mathrm{T} 2 \mathrm{I} 5 \mathrm{~F} / \mathrm{Y}$ & 1 & 2.3 & 2.1 \\
\hline M4IL* & 6 & 14.0 & 12.8 \\
\hline MI84I/V & 2 & 4.7 & 4.3 \\
\hline MI84V & 38 & 88.4 & 80.9 \\
\hline $\mathrm{A} 62 \mathrm{~V}$ & 2 & 4.7 & 4.3 \\
\hline A98G & 1 & 2.3 & 2.1 \\
\hline L74V & 3 & 7.0 & 6.4 \\
\hline L210W* & 5 & 11.6 & 10.6 \\
\hline F77L & 2 & 4.7 & 4.3 \\
\hline FII6Y & 2 & 4.7 & 4.3 \\
\hline QI5IM & 3 & 7.0 & 6.4 \\
\hline E44D & 2 & 4.7 & 4.3 \\
\hline $\mathrm{H} 208 \mathrm{Y}$ & 1 & 2.3 & 2.1 \\
\hline
\end{tabular}

Note: *TAMs.

Abbreviations: ARV, antiretroviral; NRTI, nucleoside reverse transcriptase inhibitor.

Table 5 Frequency of PI resistance

\begin{tabular}{|l|l|l|l|}
\hline $\begin{array}{l}\text { Type of } \\
\text { mutation }\end{array}$ & Frequency & $\begin{array}{l}\text { In ARV drug } \\
\text { resistance } \\
(\mathbf{n}=43)\end{array}$ & $\begin{array}{l}\text { In first-line } \\
\text { ARV failure } \\
(\mathbf{n}=47)\end{array}$ \\
\hline L33F & 1 & 2.3 & 2.1 \\
M36I & 4 & 9.3 & 8.5 \\
K20R & 4 & 9.3 & 8.5 \\
LIOI & 1 & 2.3 & 2.1 \\
A7IV & I & 2.3 & 2.1 \\
\hline
\end{tabular}

Abbreviations: $\mathrm{Pl}$, protease inhibitor; ARV, antiretroviral.

HIV-1 in Northern Vietnam did not increase from 2007 to 2009 although the rate of ART coverage was increased. ${ }^{7}$ In
Table 6 The level of resistance to first-line antiretroviral drugs for individuals

\begin{tabular}{|c|c|c|c|}
\hline Variables & $\begin{array}{l}\text { High-level } \\
\text { n (\%) }\end{array}$ & $\begin{array}{l}\text { Intermediate } \\
\text { level n (\%) }\end{array}$ & $\begin{array}{l}\text { Low-level } \\
\text { n (\%) }\end{array}$ \\
\hline \multicolumn{4}{|l|}{ NRTls } \\
\hline 3TC & $40(93.0)$ & I (2.3) & $2(4.7)$ \\
\hline$A B C$ & $13(30.2)$ & $5(11.6)$ & $25(58.2)$ \\
\hline AZT & $4(9.3)$ & $21(48.8)$ & I8 (4I.9) \\
\hline $\mathrm{d} 4 \mathrm{~T}$ & $18(4 \mid .9)$ & I5 (34.9) & $10(23.2)$ \\
\hline FTC & $40(93.0)$ & I (2.3) & $2(4.7)$ \\
\hline ddl & $15(34.9)$ & $3(7.0)$ & $25(58.1)$ \\
\hline TDF & II (25.6) & $2(4.7)$ & $30(69.7)$ \\
\hline \multicolumn{4}{|l|}{ NNRTIs } \\
\hline EFV & $24(55.8)$ & $16(37.2)$ & $3(7.0)$ \\
\hline ETR & $2(4.7)$ & I8 (4I.8) & $23(53.5)$ \\
\hline NVP & $4 \mid(95.3)$ & $0(0.0)$ & $2(4.7)$ \\
\hline \multicolumn{4}{|l|}{ Pls } \\
\hline ATV & $0(0.0)$ & $0(0.0)$ & $43(100.0)$ \\
\hline DRV & $0(0.0)$ & $0(0.0)$ & $43(100.0)$ \\
\hline FPV & $0(0.0)$ & $0(0.0)$ & $43(100.0)$ \\
\hline IDV & $0(0.0)$ & $0(0.0)$ & $43(100.0)$ \\
\hline LPV & $0(0.0)$ & $0(0.0)$ & $43(100.0)$ \\
\hline NFV & $0(0.0)$ & $0(0.0)$ & $43(100.0)$ \\
\hline SQV & $0(0.0)$ & I (2.3) & $42(97.7)$ \\
\hline TPV & $0(0.0)$ & $0(0.0)$ & $43(100.0)$ \\
\hline
\end{tabular}

Abbreviations: NRTI, nucleoside reverse transcriptase inhibitor; 3TC, lamivudine; $A B C$, abacavir; AZT, zidovudine; $d 4 T$, stavudine; ddl, didanosine; TDF, tenofovir disoproxil fumarate; NNRTI, non-nucleoside reverse transcriptase inhibitor; EFV, efavirenz; ETR, etravirine; NVP, nevirapine; PI, protease inhibitor; ATV, atazanavir; DRV, darunavir; FPV, fosamprenavir; IDV, indinavir; LPV, lopinavir; NFV, nelfinavir; SQV, saquinavir; TPV, tipranavir.

our study, $10.95 \%$ had drug resistance mutation (43 patients in total; 392 patients received treatment in Dong Da Hospital, Hanoi, from June 2006 to December 2016). The reason behind this high level was that all patients were in-patients and had been followed up continuously.

Drug resistance is an important consideration when choosing ART regimen. We noticed that four patients $(\sim 8.51 \%)$ did not show resistance-conferring mutations, and the therapeutic failure may have been due to other factors. ${ }^{17,18}$ The mutation pattern in our study was similar to the results of an ADR survey at three clinics in Ho Chi Minh City in 2009. ${ }^{19}$ In a previous pre-treatment HIV-DR study, NNRTI resistance was K103N, Y181C, Y188C and G190A, and NRTI resistance was V75M and M184V. ${ }^{20}$

TAMs occur in different patterns: type 1 includes M41L, L210W and $\mathrm{T} 215 \mathrm{Y}(14 \%, 11.6 \%$ and $4.7 \%$ prevalence, respectively, in our study), and type 2 includes K70R, D67N $\mathrm{T} 215 \mathrm{~F}$ and $\mathrm{K} 219 \mathrm{Q} / \mathrm{E}(37.2 \%, 27.9 \%, 27.9 \%$ and $14 \%$ prevalence, respectively, in our study). In our study, type 2 TAMs 
were more prevalent than type 1 TAMs. This finding indicates that type 2 TAMs had a slight negative impact on abacavir (ABC), didanosine (ddI) or TDF virological response. The accumulation of other mutations observed included TAMs (including M41L, L210W, T215Y, K70R, D67N, T215F and K219Q), resulting in increased resistance to AZT, TDF, D4T, $\mathrm{ABC}$ and ddI. ${ }^{21,22}$ The T215Y mutation was observed in 4.7\% of the sequences, whereas $\mathrm{T} 215 \mathrm{~F}$ was detected in $27.9 \%$. This result was in line with that of Yahi $\mathrm{N}$ et al, who found that $\mathrm{T} 215 \mathrm{~F}$ mutation was preferentially associated with K70R (>71\%), D67N (>73\%) and K219Q/E/N (>76\%), whereas T215Y mutation was associated with M41L (>84\%) and L210W (>58\%). ${ }^{23}$

Regarding, $88.4 \%$ of patients had HIV-DR in first-line ART failures was the M184V mutation. It was selected by lamivudine (3TC), emtricitabine (FTC) or ABC use and $3 \mathrm{TC}$ resistance with high level. ${ }^{24}$ This result was more highly observed than other mutations similar to the findings of other studies: Winand et al (M184V: 44.0\%, $\mathrm{n}=3,554)^{25}$ and El Annaz et al (M184V: 44.0\%, n=45). ${ }^{26}$ This finding can be explained by the M184V mutation in line with lamivudine (3TC) resistance. ${ }^{27}$ This drug has been proven effective in patients with chronic hepatitis $\mathrm{B}$ and is routinely used in treatment in Vietnam. ${ }^{28}$ Moreover, the prevalence of hepatitis B surface antigen (HBsAg) in the general Vietnam population ranged from $5.7 \%-24.7 \% .^{29}$ In addition, co-infection with HIV was seen in $28 \%$ of HBV-infected IDUs $(n=49 / 174)$ and $15.2 \%$ of commercial sex workers. ${ }^{30}$ Patients receiving incomplete suppressive 3TC regimens usually develop M184V as their first mutation. ${ }^{31,32}$ This mutation is related to the development of resistance to lamivudine that is part of the major concern in the standard of care provided in Vietnam.

In this study, a considerably low level of resistance to PIs was found in adults $(11.6 \%)$. The reason why PI resistance was low in patients who failed first-line treatment was probably due to the appropriate switching from first-line regimen to second-line regimen guided by the national guideline. The principle for switching is based on ART history, drug resistance test and monitoring during the first 3 months after switch in. ${ }^{10}$ Vietnam's standard second-line PI-based therapies included TDF/ 3TC or ddI/ABC plus lopinavir/ritonavir. ${ }^{10}$ The high efficacy of lopinavir/ritonavir monotherapy in second-line regimens was able to achieve full viral suppression for individuals failing first-line treatment. ${ }^{33}$ In Vietnam, the prevalence of PI resistance was high in patients failing second-line ART. ${ }^{34}$ In our study, the emergence of
PI resistance at the time of first-line virological failure was uncommon (only one patient resisted to saquinavir in intermediate level. No lopinavir/ritonavir resistance was recorded).

\section{Conclusion}

Drug resistance mutations in patients with first-line ART failures had a high prevalence of NNRTIs and NRTI resistance but are still susceptible to PIs.

\section{Abbreviations}

ART, antiretroviral therapy; RT, Reverse Transcriptase; ARV, antiretroviral; HIV-DR, HIV-1 drug resistance.

\section{Disclosure}

The authors report no conflicts of interest in this work.

\section{References}

1. HIV/AIDS. World Health Organization. Fact sheet [Internet] http://www.who.int/news-room/fact-sheets/detail/hiv-aids. Accessed November 27, 2018.

2. Stadeli KM, Richman DD. Rates of emergence of HIV drug resistance in resource-limited settings: a systematic review. Antivir Ther. 2013;18(1):115-123. doi:10.3851/IMP2437

3. Taniguchi T, Nurutdinova D, Grubb JR, et al. Transmitted drug-resistant HIV type 1 remains prevalent and impacts virologic outcomes despite genotype-guided antiretroviral therapy. AIDS Res Hum Retroviruses. 2012;28(3):259-264. doi:10.1089/aid.2011.0022

4. Ruperez M, Pou C, Maculuve S, et al. Determinants of virological failure and antiretroviral drug resistance in Mozambique. $J$ Antimicrob Chemother. 2015;70(9):2639-2647. doi:10.1093/jac/dkv143

5. Dean J, Ta Thi TH, Dunford L, et al. Prevalence of HIV type 1 antiretroviral drug resistance mutations in Vietnam: a multicenter study. AIDS Res Hum Retroviruses. 2011;27(7):797-801. doi:10.1089/aid.2011.0013

6. Bontell I, Cuong Do D, Agneskog E, Diwan V, Larsson M, Sonnerborg A. Transmitted drug resistance and phylogenetic analysis of HIV CRF01 AE in Northern Vietnam. Infect Genet Evol. 2012;12 (2):448-452. doi:10.1016/j.meegid.2011.04.034

7. Tran VT, Ishizaki A, Nguyen $\mathrm{CH}$, et al. No increase of drug-resistant HIV type 1 prevalence among drug-naive individuals in Northern Vietnam. AIDS Res Hum Retroviruses. 2012;28(10):1349-1351. doi:10.1089/aid.2012.0006

8. Tanuma J, Quang VM, Hachiya A, et al. Low prevalence of transmitted drug resistance of HIV-1 during 2008-2012 antiretroviral therapy scaling up in Southern Vietnam. J Acquir Immune Defic Syndr. 2014;66(4):358-364. doi:10.1097/QAI.0000000000000196

9. Wittkop L, Gunthard HF, de Wolf F, et al. Effect of transmitted drug resistance on virological and immunological response to initial combination antiretroviral therapy for HIV (EuroCoord-CHAIN joint project): a European multicohort study. Lancet Infect Dis. 2011;11 (5):363-371. doi:10.1016/S1473-3099(11)70032-9

10. The National Guidelines for Diagnosis and Treatment of HIV/AIDS Vietnamese Ministry of Health. Hanoi: Ministry of Health; 2009.

11. The National Guidelines for Diagnosis and Treatment of HIV/AIDS. Vietnamese Ministry of Health. Hanoi: Ministry of Health; 2005.

12. Antiretroviral Therapy for HIV Infection in Adults and Adolescents: Recommendations for a Public Health Approach. World Health Organization. Geneva: Author; 2006. 
13. Kuritzkes DR, Grant RM, Feorino P, et al. Performance characteristics of the TRUGENE HIV-1 genotyping kit and the opengene DNA sequencing system. J Clin Microbiol. 2003;41(4):1594-1599.

14. Nguyen HT, Duc NB, Shrivastava R, et al. HIV drug resistance threshold survey using specimens from voluntary counselling and testing sites in Hanoi, Vietnam. Antivir Ther. 2008;13:115.

15. Ayouba A, Lien TT, Nouhin J, et al. Low prevalence of HIV type 1 drug resistance mutations in untreated, recently infected patients from Burkina Faso, Cote d'Ivoire, Senegal, Thailand, and Vietnam: the ANRS 12134 study. AIDS Res Hum Retroviruses. 2009;25 (11):1193-1196. doi:10.1089/aid.2009.0142

16. Duc NB, Hien BT, Wagar N, et al. Surveillance of transmitted HIV drug resistance using matched plasma and dried blood spot specimens from voluntary counseling and testing sites in Ho Chi Minh City, Vietnam, 2007-2008. Clin Infect Dis. 2012;54(suppl_4):S343S347. doi:10.1093/cid/cir1049

17. UK Collaborative Group on HIV Drug Resistance; UK CHIC Study Group.Long-term probability of detecting drug-resistant HIV in treatment-naive patients initiating combination antiretroviral therapy. Clin Infect Dis. 2010;50(9):1275-1285. doi:10.1086/651684

18. Chesney MA, Ickovics J, Hecht FM, Sikipa G, Rabkin J. Adherence: a necessity for successful HIV combination therapy. AIDS. 1999;13 Suppl A:S271-S278.

19. Aghokeng AF, Monleau M, Eymard-Duvernay S, et al. Extraordinary heterogeneity of virological outcomes in patients receiving highly antiretroviral therapy and monitored with the World Health Organization public health approach in sub-saharan Africa and southeast Asia. Clin Infect Dis. 2014;58(1):99-109. doi:10.1093/cid/cit627

20. Pham QD, Do NT, Le YN, et al. Pretreatment HIV-1 drug resistance to first-line drugs: results from a baseline assessment of a large cohort initiating ART in Vietnam, 2009-10. J Antimicrob Chemother. 2015;70(3):941-947. doi:10.1093/jac/dku473

21. Van Vaerenbergh K, Van Laethem K, Albert J, et al. Prevalence and characteristics of multinucleoside-resistant human immunodeficiency virus type 1 among European patients receiving combinations of nucleoside analogues. Antimicrob Agents Chemother. 2000;44(8):2109-2117.

22. Coakley EP, Gillis JM, Hammer SM. Phenotypic and genotypic resistance patterns of HIV-1 isolates derived from individuals treated with didanosine and stavudine. AIDS. 2000;14(2):F9-15.

23. Yahi N, Fantini J, Henry M, Tourres C, Tamalet C. Structural analysis of reverse transcriptase mutations at codon 215 explains the predominance of T215Y over T215F in HIV-1 variants selected under antiretroviral therapy. J Biomed Sci. 2005;12(5):701-710. doi:10.1007/s11373-005-9011-4
24. Johnson VA, Calvez V, Gunthard HF, et al. 2011 update of the drug resistance mutations in HIV-1. Top Antivir Med. 2011;19(4):156-164.

25. Winand R, Theys K, Eusebio M, et al. Assessing transmissibility of HIV-1 drug resistance mutations from treated and from drug-naive individuals. AIDS. 2015;29(15):2045-2052. doi:10.1097/QAD.000 0000000000811

26. El Annaz H, Recordon-Pinson P, Tagajdid R, et al. Drug resistance mutations in HIV type 1 isolates from patients failing antiretroviral therapy in Morocco. AIDS Res Hum Retroviruses. 2012;28 (8):944-948. doi:10.1089/AID.2011.0278

27. Miller V, Stark T, Loeliger AE, Lange JM. The impact of the M184V substitution in HIV-1 reverse transcriptase on treatment response. HIV Med. 2002;3(2):135-145.

28. Liaw Y-F, Sung JJ, Chow WC, et al. Lamivudine for patients with chronic hepatitis B and advanced liver disease. $N$ Engl J Med. 2004;351(15):1521-1531. doi:10.1056/NEJMoa033364

29. Sereno L, Mesquita F, Kato M, Jacka D, Nguyen TT, Nguyen TN. Epidemiology, responses, and way forward: the silent epidemic of viral hepatitis and HIV coinfection in Vietnam. J Int Assoc Physicians AIDS Care (Chic). 2012;11(5):311-320. doi:10.1177/ 1545109712453939

30. Dunford L, Carr MJ, Dean J, et al. A multicentre molecular analysis of hepatitis B and blood-borne virus coinfections in Viet Nam. PLoS One. 2012;7(6):e39027. doi:10.1371/journal.pone.0039027

31. Geretti AM. Clinical implications of HIV drug resistance to nucleoside and nucleotide reverse transcriptase inhibitors. AIDS Rev. 2006;8 (4):210-220.

32. Theys K, Deforche K, Libin P, Camacho RJ, Van Laethem K, Vandamme AM. Resistance pathways of human immunodeficiency virus type 1 against the combination of zidovudine and lamivudine. $J$ Gen Virol. 2010;91(Pt 8):1898-1908. doi:10.1099/vir.0.022 657-0

33. Bartlett JA, Ribaudo HJ, Wallis CL, et al. Lopinavir/ritonavir monotherapy after virologic failure of first-line antiretroviral therapy in resource-limited settings. AIDS. 2012;26(11):1345-1354. doi:10.1097/QAD.0b013e328353b066

34. Thao VP, Quang VM, Day JN, et al. High prevalence of PI resistance in patients failing second-line ART in Vietnam. $J$ Antimicrob Chemother. 2016;71(3):762-774. doi:10.1093/jac/dkv385
Infection and Drug Resistance

\section{Publish your work in this journal}

Infection and Drug Resistance is an international, peer-reviewed openaccess journal that focuses on the optimal treatment of infection (bacterial, fungal and viral) and the development and institution of preventive strategies to minimize the development and spread of resistance. The journal is specifically concerned with the epidemiology of antibiotic resistance and the mechanisms of resistance development and diffusion in both hospitals and the community. The manuscript management system is completely online and includes a very quick and fair peerreview system, which is all easy to use. Visit http://www.dovepress.com/ testimonials.php to read real quotes from published authors. 